\title{
Identification of Four Distinct Regions of Allelic Imbalances on Chromosome 1 by the Combined Comparative Genomic Hybridization and Microsatellite Analysis on Hepatocellular Carcinoma
}

Thomas H.-Y. Leung, B.Sc., Nathalie Wong, D.Phil., Paul B.-S. Lai, M.B. Ch.B., F.R.C.S.Ed., Andrew Chan, Ph.D., Ka-Fai To, M.B. Ch.B., F.R.C.P.A., Choong-Tsek Liew, M.D., F.C.A.P., WanYee Lau, M.B. B.S., F.R.C.S., Philip J. Johnson, M.D., F.R.C.P.

Department of Clinical Oncology (TH-YL, NW, PJJ), Institute of Molecular Oncology (TH-YL, NW, AC, PJJ), Department of Surgery (PB-SL), and Department of Anatomical and Cellular Pathology (K-FT, C-TL), Sir

Y.K. Pao Centre for Cancer, The Chinese University of Hong Kong, Prince of Wales Hospital, Shatin, Hong Kong

Frequent chromosome 1 abnormalities detected in human hepatocellular carcinoma have been implicated in early genetic events of liver carcinogenesis. Recurrent loss of $1 p$ with a common deleted region 1p36-p34 has been reported from microsatellite analysis, whereas common gain of the whole chromosome q-arm was described from several comparative genomic hybridization studies. The relationships between copy number changes and allelic status however remains unclear. In this study, we have conducted a simultaneous comparative genomic hybridization and microsatellite analysis study on chromosome 1 in 31 hepatocellular carcinoma cases. Microsatellite analysis revealed frequent loss of heterozygosity on 1p at loci D1S468 (74\%), D1S450 (67\%), D1S2667 (65\%), D1S2697 (75\%), D1S199 (52\%), and D1S234 (67\%) corresponded to the distal 1 p36 region and coincided with 12 cases $(86 \%)$ that presented losses on $1 p$ by comparative genomic hybridization analysis. Although comparative genomic hybridization indicated a common deleted region of 1 p36-p35 in the current series, microsatellite analysis has refined the smallest overlapping region (SOR) to 1p36.13p36.22. Gain of $1 \mathrm{q}$ as revealed by comparative genomic hybridization suggested low and high-level gains, and cases that displayed an amplicon below the heterochromatic region 1q21-q25. Common al-

Copyright $\odot 2002$ by The United States and Canadian Academy of Pathology, Inc.

VOL. 15, NO. 11, P. 1213, 2002 Printed in the U.S.A.

Date of acceptance: August 7, 2002.

Address reprint requests to: Nathalie Wong, D.Phil., Department of Clinical Oncology, The Chinese University of Hong Kong, Prince of Wales Hospital,

Shatin, N. T., SAR Hong Kong, China; e-mail: natwong@cuhk.edu.hk; fax: $-852-2648-8842$

DOI: 10.1097/01.MP.0000036347.66943.3C lelic imbalances of polymorphic markers D1S2635 (64\%), D1S484 (67\%), D1S2878 (65\%), D1S196 (70\%), D1S249 (64\%) D1S2785 (75\%), D1S2842 (73\%) and D1S2836 (74\%) that corresponded to the regions 1q23.1-q24.2, 1q32.1 and 1q43-q44 were detected. Three distinct regions of allelic imbalances were thus suggested on recurring 1q gain found in hepatocellular carcinoma. Furthermore, microsatellite analysis has enabled a mapping of common overrepresented regions and suggested SOR on 1q23.1-q23.3 (D1S2635-D1S2878), 1q25.1q31.1 (D1S452-D1S238), and 1q43 (D1S2785D1S2842). Our current study has refined chromosome 1 aberrations in hepatocellular carcinoma to four regions of allelic imbalances. The SORs delineated should provide basis for further molecular investigation in hepatocarcinogenesis on genes residing on these chromosomal regions.

KEY WORDS: Allelic imbalances, Chromosome 1, Comparative genomic hybridization, Hepatocellular carcinoma, Microsatellite analysis.

Mod Pathol 2002;15(11):1213-1220

Hepatocellular carcinoma is a highly malignant tumor that is prevalent in Southeast Asia, China, and sub-Saharan Africa. It has a high mortality rate, and recurrence after surgical resection is common. Risk factors, including viral hepatitis Types $B$ and $C$ infection and dietary aflatoxin, are well recognized in hepatocellular carcinoma, but the pathways by which malignant transformation of hepatocytes occurs remains unclear.

Recurrent genetic alterations in hepatocellular carcinoma have been reported from microsatellite analysis and comparative genomic hybridization (CGH) studies (1-3). Using CGH, we and others 
have detected recurrent gains of $1 \mathrm{q}, 6 \mathrm{p}, 8 \mathrm{q}, 17 \mathrm{q}$ and $20 q$ and losses of $1 p, 4 q, 8 p, 13 q, 16 q$ and $17 p(4-6)$. Among the common aberrations observed, loss of heterozygosity (LOH) of 1p36-p34 has been identified in the putative premalignant cirrhotic nodules and, by using centromeric probes, chromosome 1 polysomy has been reported in liver dysplasia by interphase cytogenetics $(7,8)$. Thus, deletions on distal $1 p$ and 1q copy gains have been implicated in the early stages of hepatocellular carcinoma development.

In this study, we conducted a simultaneous CGH and microsatellite analysis study on 31 hepatocellular carcinoma cases, aiming to characterize the nature of the chromosome 1 abnormalities. Microsatellite analysis on chromosome 1 was carried out using a panel of 31 polymorphic markers that spanned approximately $5-10 \mathrm{cM}$. This combined CGH and microsatellite analysis identified four distinct regions of allelic imbalances on chromosome 1 , and microsatellite analysis has enabled the smallest overlapping regions (SORs) in deletions and high-level gains, as identified by CGH, to be defined.

\section{MATERIALS AND METHODS}

\section{Patients}

Tumorous liver tissues were obtained from patients (aged $34-76$ years) who underwent curative liver surgery for hepatocellular carcinoma at the Prince of Wales Hospital, Hong Kong. Tumor samples from 31 hepatocellular carcinoma patients $(77 \%$ male) and the corresponding peripheral blood from the same patient were collected. One patient had 2 foci, H29a and H29b. Patients recruited in the present series were predominantly viral hepatitis B carriers (84\%). The clinicopathological information of hepatocellular carcinoma patients studied is summarized in Table 1. An experienced pathologist confirmed the diagnosis of hepatocellular carcinoma and evaluated all tumor specimens for the tumor cell content. High molecular weight genomic DNA from tumor tissues and blood leukocytes was extracted by QIAamp Tissue kit and QIAamp Blood kit (Qiagen, Hilden, Germany) respectively.

\section{Comparative Genomic Hybridization}

Comparative genomic hybridization (CGH) was performed according to the method of Kallioniemi et al. (9), with modifications described in Wong et al. (6). One microgram of tumor and reference DNA was differentially labeled with biotin-16-dUTP (Boehringer Mannheim, Mannheim, Germany) and digoxigenin (dig)-11-dUTP (Boehringer Mannheim), respectively by nick translation. Labeled

TABLE 1. Clinicopathologic Characteristics and CGH Findings on Chromosome 1 in 31 Cases of HCC

\begin{tabular}{|c|c|c|c|c|c|c|c|c|c|}
\hline \multirow{2}{*}{ Case } & \multirow{2}{*}{ Age (y) } & \multirow{2}{*}{ Sex } & \multirow{2}{*}{$\begin{array}{l}\text { TNM } \\
\text { Stage }\end{array}$} & \multirow{2}{*}{ Cirrhosis } & \multirow{2}{*}{$\begin{array}{l}\text { Tumor Size } \\
(\mathrm{cm})\end{array}$} & \multirow{2}{*}{$\begin{array}{l}\text { Viral } \\
\text { Status }\end{array}$} & \multicolumn{3}{|c|}{ CGH Findings } \\
\hline & & & & & & & Loss & Gain & Amplification \\
\hline $\mathrm{H} 1$ & 54 & M & $\mathrm{T} 2$ & + & 2.7 & HBV & 1pter-p21 & - & 1p21-q25, 1q32-qter \\
\hline $\mathrm{H} 2$ & 38 & $\mathrm{M}$ & $\mathrm{T} 2$ & + & 3 & HBV & $1 \mathrm{p}$ & - & $1 \mathrm{q}$ \\
\hline H3 & 64 & M & $\mathrm{T} 2$ & + & 3.4 & HBV & $1 \mathrm{p}$ & - & $1 \mathrm{q}$ \\
\hline $\mathrm{H} 4$ & 58 & $\mathrm{~F}$ & $\mathrm{~T} 2$ & - & 7 & HBV & $1 \mathrm{p} 35-\mathrm{p} 21$ & $1 \mathrm{p} 36,1 \mathrm{q}$ & - \\
\hline H5 & 45 & M & $\mathrm{T} 2$ & - & 2.2 & $\mathrm{HBV}$ & - & $1 \mathrm{q}$ & - \\
\hline H6 & 51 & $\mathrm{~F}$ & $\mathrm{~T} 2$ & + & 2.6 & - & $1 \mathrm{p}$ & $1 \mathrm{q}$ & - \\
\hline $\mathrm{H} 7$ & 40 & M & $\mathrm{T} 2$ & - & 6.5 & $\mathrm{HBV}$ & 1pter-p34.2 & - & $1 q 21-q 31$ \\
\hline H8 & 51 & M & $\mathrm{T} 2$ & + & 4.5 & $\mathrm{HBV}$ & 1pter-p34.2 & $1 \mathrm{p} 31-\mathrm{p} 13,1 \mathrm{q} 31-\mathrm{q} 41$ & $1 q 21-q 31$ \\
\hline H9 & 48 & M & T3 & + & 3.4 & HBV & 1pter-p34.3 & - & $1 \mathrm{p} 31-\mathrm{p} 21,1 \mathrm{q} 21-\mathrm{q} 25$ \\
\hline H10 & 53 & $\mathrm{~F}$ & T3 & + & 4.4 & $\mathrm{HBV}$ & 1pter-p31 & $1 \mathrm{p} 22-\mathrm{p} 12$ & $1 \mathrm{q}$ \\
\hline H11 & 76 & $\mathrm{~F}$ & $\mathrm{~T} 2$ & - & 2.8 & - & - & - & $1 \mathrm{q}$ \\
\hline H12 & 60 & M & $\mathrm{T} 4$ & - & 4.8 & HBV & - & $1 \mathrm{q}$ & $1 q 21-q 31$ \\
\hline H13 & 67 & M & $\mathrm{T} 2$ & + & 3.5 & $\mathrm{HCV}$ & - & - & 1q21-qter \\
\hline $\mathrm{H} 14$ & 44 & M & T3 & - & 6 & $\mathrm{HBV}$ & 1pter-p33 & $1 \mathrm{q}$ & - \\
\hline H15 & 34 & $\mathrm{~F}$ & $\mathrm{~T} 2$ & + & 3.2 & $\mathrm{HBV}$ & - & $1 q 25-q 32$ & 1q32-qter \\
\hline H16 & 43 & M & $\mathrm{T} 2$ & - & 8.3 & $\mathrm{HBV}$ & 1pter-p35 & $1 \mathrm{p} 33-\mathrm{p} 21,1 \mathrm{q} 21-\mathrm{q} 31$ & - \\
\hline H17 & 47 & M & T3 & + & 2.3 & $\mathrm{HCV}$ & 1pter-p34 & $1 \mathrm{q} 21-\mathrm{q} 25$ & - \\
\hline H18 & 40 & $\mathrm{M}$ & $\mathrm{T} 4$ & + & 5.5 & HBV & - & 1p34.2-qter & - \\
\hline H19 & 70 & $\mathrm{M}$ & $\mathrm{T} 2$ & - & 2.2 & $\mathrm{HBV}$ & - & 1p31-p11 & 1q21.3-q31 \\
\hline $\mathrm{H} 20$ & 58 & $\mathrm{M}$ & $\mathrm{T} 2$ & - & 4.5 & $\mathrm{HBV}$ & - & $1 q 21-q 32$ & - \\
\hline $\mathrm{H} 21$ & 72 & $\mathrm{M}$ & $\mathrm{T} 2$ & + & 2.4 & $\mathrm{HBV}$ & 1pter-p33 & - & - \\
\hline H22 & 57 & M & $\mathrm{T} 2$ & - & 8 & $\mathrm{HBV}$ & - & $1 \mathrm{p} 31-\mathrm{p} 22,1 \mathrm{q} 21-\mathrm{q} 32$ & - \\
\hline H23 & 45 & $\mathrm{M}$ & $\mathrm{T} 2$ & + & 9.8 & $\mathrm{HBV}$ & - & $1 \mathrm{q} 21-\mathrm{q} 25$ & - \\
\hline $\mathrm{H} 24$ & 70 & $\mathrm{~F}$ & $\mathrm{~T} 2$ & - & 2.2 & HBV & - & $1 q 21-q 43$ & - \\
\hline H25 & 72 & M & T3 & - & 8 & - & 1pter-p32 & $1 \mathrm{q}$ & - \\
\hline H26 & 60 & $\mathrm{M}$ & T3 & + & 2.4 & HBV & - & 1p13-qter & - \\
\hline $\mathrm{H} 27$ & 43 & $\mathrm{M}$ & $\mathrm{T} 4$ & NA & 4.4 & HBV & - & $1 q 21-q 25$ & - \\
\hline H28 & 43 & $\mathrm{M}$ & $\mathrm{T} 1$ & + & 1.8 & HBV & - & $1 q 21-q 43$ & - \\
\hline $\mathrm{H} 29 \mathrm{a}$ & 42 & $\mathrm{M}$ & T3 & + & 4 & HBV & - & - & - \\
\hline $\mathrm{H} 29 \mathrm{~b}$ & 42 & $\mathrm{M}$ & $\mathrm{T} 3$ & + & 4 & $\mathrm{HBV}$ & - & - & - \\
\hline Н30 & 51 & $\mathrm{~F}$ & $\mathrm{~T} 2$ & - & 13.5 & $\mathrm{HBV}$ & - & - & $1 q 21-q 25$ \\
\hline H31 & 69 & M & $\mathrm{T} 2$ & + & 6.5 & $\mathrm{HBV}$ & - & - & $1 \mathrm{q}$ \\
\hline
\end{tabular}


DNAs were co-hybridized onto normal metaphase chromosomes in excess Cot-1 DNA. After hybridization, biotin signals were detected through avidin-conjugated FITC (fluorescein isothiocyanate) antibody (Sigma, St Louis, MO), and diglabeled DNA was visualized by TRITC (tetramethylrhodamine isothiocyanate)-conjugated antibody (Sigma). Chromosomes counterstained with DAPI (4',6-diamidino-2-phenylindole) were captured through a cooled CCD camera mounted on a Leitz DM RB (Leica, Wetzlar, Germany) fluorescence microscope. Three band-pass filter sets (DAPI, FITC, and TRITC) arranged in an automated filter wheel were employed for image acquisition. CGH software version 3.1 on Cytovision (Applied Imaging Ltd., U.K.) was used in digital image analysis. Average ratio profiles of 10-12 metaphases were calculated based on chromosome identification of the inverted DAPI image. Thresholds for gains and losses were defined as theoretical values of 1.25 and 0.75 , respectively. High-level amplifications were considered when ratio exceeded 1.5.

\section{Microsatellite Analysis}

Thirty-one fluorescent-labeled polymorphic markers, 16 on $1 p$ and 15 on 1q, were acquired from ABI PRISM Linkage Mapping Sets (Applied Biosystems, Foster City, CA). PCR was performed in $7.5 \mu \mathrm{L}$ reaction buffer (Perkin Elmer, Foster City, CA) that contained $30 \mathrm{ng}$ of genomic DNA, $5 \mu \mathrm{m}$ primer pair mix, $2.5 \mathrm{~mm}$ GeneAmp dNTP mix, $25 \mathrm{~mm} \mathrm{MgCl}_{2}$, and 5 units AmpliTaq Gold DNA Polymerase (Applied Biosystems). The reaction was performed using the GeneAmp PCR System 9600. The PCR conditions consisted of an initial denaturation step at $95^{\circ} \mathrm{C}$ for 12 minutes, followed by 10 cycles of denaturation at $94^{\circ} \mathrm{C}$ for 15 seconds, annealing at $55^{\circ}$ $\mathrm{C}$ for 15 seconds, and extension at $72^{\circ} \mathrm{C}$ for 30 seconds. A further 20 cycles was carried out at $89^{\circ} \mathrm{C}$ denaturation for 15 seconds, annealing at $55^{\circ} \mathrm{C}$ for 15 seconds, and extension at $72^{\circ} \mathrm{C}$ for 30 seconds. The final extension was performed after the 30th cycle at $72^{\circ} \mathrm{C}$ for 10 minutes. Amplified DNA products were analyzed on 5\% Long Ranger denaturing gel in TBE buffer. Electrophoresis was run on an automated sequencer ABI 377 (PE Biosystems). Data collected were analyzed by Genescan software. Cases were classified as informative when two distinct alleles of similar intensity were found in the normal DNA and were classified as allelic loss or allelic imbalance when $\geq 50 \%$ intensity differences were present between tumor and normal DNAs. Cases of homozygosity were considered noninformative. Examples of allelic imbalances detected in hepatocellular carcinoma are shown in Figure 3.

\section{RESULTS}

\section{Comparative Genomic Hybridization}

Among 31 cases analyzed, partial and wholechromosome $1 \mathrm{p}$ loss were detected in 14 cases (45\%). A minimal overlapping region on 1 p36-p35 was also determined. Gains of partial or whole chromosome $1 q$ were found in 29 cases (94\%). Furthermore, high-level gain of regional or whole $1 \mathrm{q}$ was suggested in 14 of 29 that displayed copy gain (48\%). An overlapping region was narrowed down to $1 \mathrm{q} 21-\mathrm{q} 25$ and 1q32-qter. CGH imbalances on chromosome 1 were not detected in H29a and H29b. Furthermore, H29a and H29b displayed similar aberrations in CGH analysis and microsatellite analysis. This suggested that both specimens shared a similar clonal origin. In the calculation of percentage incidences, we have therefore scored $\mathrm{H} 29 \mathrm{a}$ and $\mathrm{H} 29 \mathrm{~b}$ as one case. The CGH results obtained are summarized in Table 1, and examples of average ratio profiles on aberrant chromosome 1 are shown in Figure 1.

\section{Microsatellite Analysis}

Using 31 polymorphic markers, markers with allelic imbalances in $>40 \%$ of informative cases were observed at 24 loci (Table 2). The highest incidences of allelic imbalance identified in the 31 pairs of matched hepatocellular carcinoma and leukocyte-derived DNA were D1S468 at 74\% (1p36.32), D1S450 at $67 \%$ (1p36.23), D1S2667 at 65\% (1p36.22), D1S2697 at 75\% (1p36.21), D1S199 at 52\% (1p36.13), and D1S234 at $67 \%$ (1p36.11). All loci represented regions on the distal $1 p$ region at $1 p 36$. On chromosome $1 q$, frequent allelic imbalances were detected on D1S2635 at $64 \%$ (1q23.1), D1S484 at 67\% (1q23.2), D1S2878 at 65\% (1q23.3), D1S196 at $70 \%$ (1q24.2), D1S249 at $64 \%$ (1q32.1), D1S2785 at $75 \%$ (1q43), D1S2842 at $73 \%$ (1q43) and D1S2836 at 74\% (1q44). These regions also lay within the minimal amplified regions identified by the parallel $\mathrm{CGH}$ analysis. The allelic imbalances found and their corresponding locations are shown in Figure 2.

Overall, 26/31 cases (84\%) of the tumors studied displayed allelic imbalances on $1 \mathrm{p}$, and $28 / 31$ cases $(90 \%)$, on $1 \mathrm{q}$ for one or more markers. Only 7 cases showed losses in $1 \mathrm{p}$ at all informative markers tested, and 3 cases displayed allelic gains in $1 q$ at all informative markers tested. Four distinct regions of SOR were further determined from the microsatellite analysis findings, these being 1p36.13-p36.22 (D1S199-D1S2667), 1q23.1-1q23.3 (D1S2635D1S2878), 1q25.1-q31.1 (D1S452-D1S238) and 1q43 (D1S2785-D1S2842). The SOR of allelic imbalance was defined based on the common deleted region among cases, which showed interstitial allelic imbalances. For the region 1p36, the upper boundary 
A

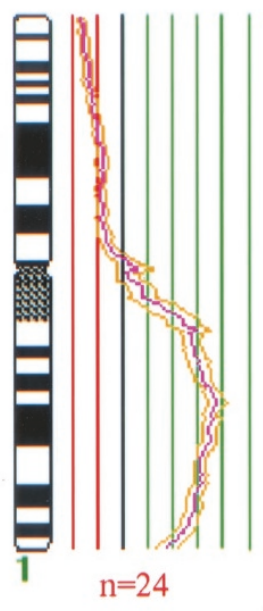

H3
B

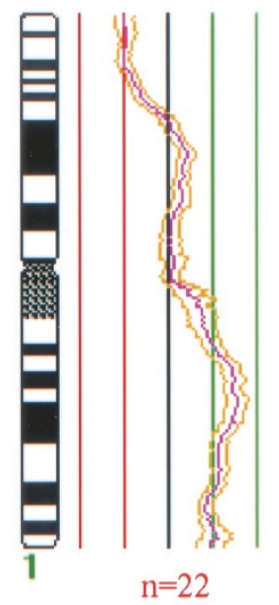

H14
C

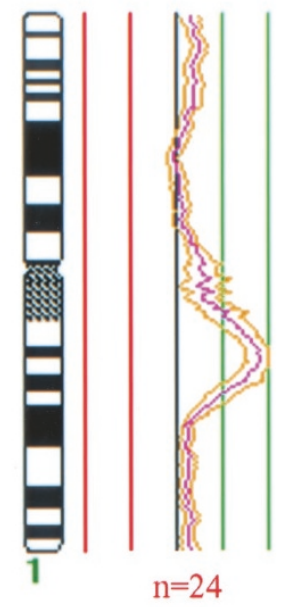

H30

FIGURE 1. Chromosome 1 imbalances detected by CGH. The mean ratio profile of $22-24$ analyzed chromosomes $(n=22-24)$ is depicted with the 95\% confidence interval (gold lines). Red and green lines represent thresholds for the chromosomal losses (0.75) and gains (1.25), respectively. A, case H3. Loss of entire p-arm and high-level gain of the entire q-arm were suggested. B, case H14 displayed regional loss of p-arm at 1p33-pter and low-level copy number gain of the entire q-arm. C, Case H30, absence of p-arm imbalances and regional amplification of 1q21-q25 were indicated.

was defined by cases $\mathrm{H} 29 \mathrm{a}$ and $\mathrm{H} 29 \mathrm{~b}$ that showed retention at D1S450 and allelic imbalances between D1S199 and D1S2667. The lower boundary was defined by case $\mathrm{H} 21$, which showed retention at locus D1S234 and allelic imbalances between D1S199 and D1S468. The SOR on 1p36 was thus defined between D1S199-D1S2667. Similar analysis was performed in defining the SORs on 1q.

\section{$\mathrm{CGH}$ versus microsatellite analysis}

Concordance between microsatellite analysis and CGH findings on chromosome 1 imbalances was found in $>60 \%$ of the cases. On the p-arm, deletions defined as being $\mathrm{CGH}[-]$, microsatellite analysis[-] were found in 13 cases (H1-4, H6-10, H14, H16, H17, and H21), whereas absence of aberrant $1 p$ defined as $\mathrm{CGH}[0]$, microsatellite analysis[0] was found in 7 cases (H23, H24, H26-28, H30, and H31). The overall concordant rate on the p-arm was $65 \%$ (20/31 cases).

Whole q-arm gain, as indicated by CGH, was frequent, but regional imbalances on the q-arm were suggested from microsatellite analysis. In cal culating the concordance rate on the $1 \mathrm{q}$ arm, we have simplified the analysis by subdividing the q-arm into three regions, namely 1q21-q25, 1q31-q32, and 1q42-q44. In 1q21-q25, CGH gain and allelic imbalances, as defined by $\mathrm{CGH}[+]$ microsatellite analysis[+], were found in 20 cases (H1-4, H6-8, H11, H14, H18, H19, H22-28, H30, and H31). There was absence of regional changes as defined by CGH[0]microsatellite analysis[0] in three cases (H15, $\mathrm{H} 21$, and H29). The overall concordance rate on 1q21-q25 was $74 \%$ (23/31 cases). In 1q31-q32, CGH[+]microsatellite analysis[+] was found in 14 cases $\left(\mathrm{H} 2-7, \mathrm{H} 10, \mathrm{H} 15, \mathrm{H}_{2} \mathrm{O}, \mathrm{H} 22, \mathrm{H} 24, \mathrm{H} 25, \mathrm{H} 28\right.$, and

TABLE 2. Frequency of Allelic Imbalances Detected on Chromosome 1

\begin{tabular}{|c|c|c|c|}
\hline $\begin{array}{l}\text { Polymorphic } \\
\text { Marker }\end{array}$ & $\begin{array}{l}\text { Chromosome } \\
\text { Location }\end{array}$ & $\begin{array}{c}\text { Percentage of } \\
\text { Informative Cases } \\
\text { (informative/total) }\end{array}$ & $\begin{array}{c}\text { Percentage of } \\
\text { Allelic Imbalance } \\
\text { (allelic imbalance/ } \\
\text { informative) }\end{array}$ \\
\hline D1S468 & 1p36.32 & 74 & 74 \\
\hline D1S214 & 1p36.31 & 16 & 80 \\
\hline D1S450 & $1 \mathrm{p} 36.23$ & 87 & 67 \\
\hline D1S2667 & 1p36.22 & 74 & 65 \\
\hline D1S2697 & $1 p 36.21$ & 39 & 75 \\
\hline D1S199 & $1 p 36.13$ & 68 & 52 \\
\hline D1S234 & $1 p 36.11$ & 58 & 67 \\
\hline D1S255 & 1p34.3 & 45 & 71 \\
\hline D1S2797 & 1p34.1 & 81 & 48 \\
\hline D1S230 & 1p31.3 & 65 & 30 \\
\hline D1S2841 & 1p31.1 & 77 & 29 \\
\hline D1S207 & 1p31.1 & 81 & 32 \\
\hline D1S2868 & $1 \mathrm{p} 22.1$ & 58 & 28 \\
\hline D1S206 & $1 \mathrm{p} 21.2$ & 71 & 27 \\
\hline D1S2726 & $1 \mathrm{p} 13.3$ & 42 & 38 \\
\hline D1S252 & $1 \mathrm{p} 13.1$ & 48 & 20 \\
\hline D1S498 & $1 q 21.3$ & 71 & 45 \\
\hline D1S2635 & $1 q 23.1$ & 45 & 64 \\
\hline D1S484 & $1 q 23.2$ & 48 & 67 \\
\hline D1S2878 & 1q23.3 & 55 & 65 \\
\hline D1S196 & $1 q 24.2$ & 65 & 70 \\
\hline D1S452 & $1 q 25.1$ & 61 & 47 \\
\hline D1S238 & $1 \mathrm{q} 31.1$ & 61 & 53 \\
\hline D1S413 & $1 q 31.3$ & 71 & 55 \\
\hline D1S249 & $1 q 32.1$ & 81 & 64 \\
\hline D1S425 & $1 \mathrm{q} 32.3$ & 45 & 64 \\
\hline D1S213 & $1 \mathrm{q} 42.13$ & 58 & 61 \\
\hline D1S2800 & $1 \mathrm{q} 42.2$ & 48 & 53 \\
\hline D1S2785 & $1 \mathrm{q} 43$ & 90 & 75 \\
\hline D1S2842 & $1 \mathrm{q} 43$ & 71 & 73 \\
\hline D1S2836 & $1 \mathrm{q} 44$ & 74 & 74 \\
\hline
\end{tabular}




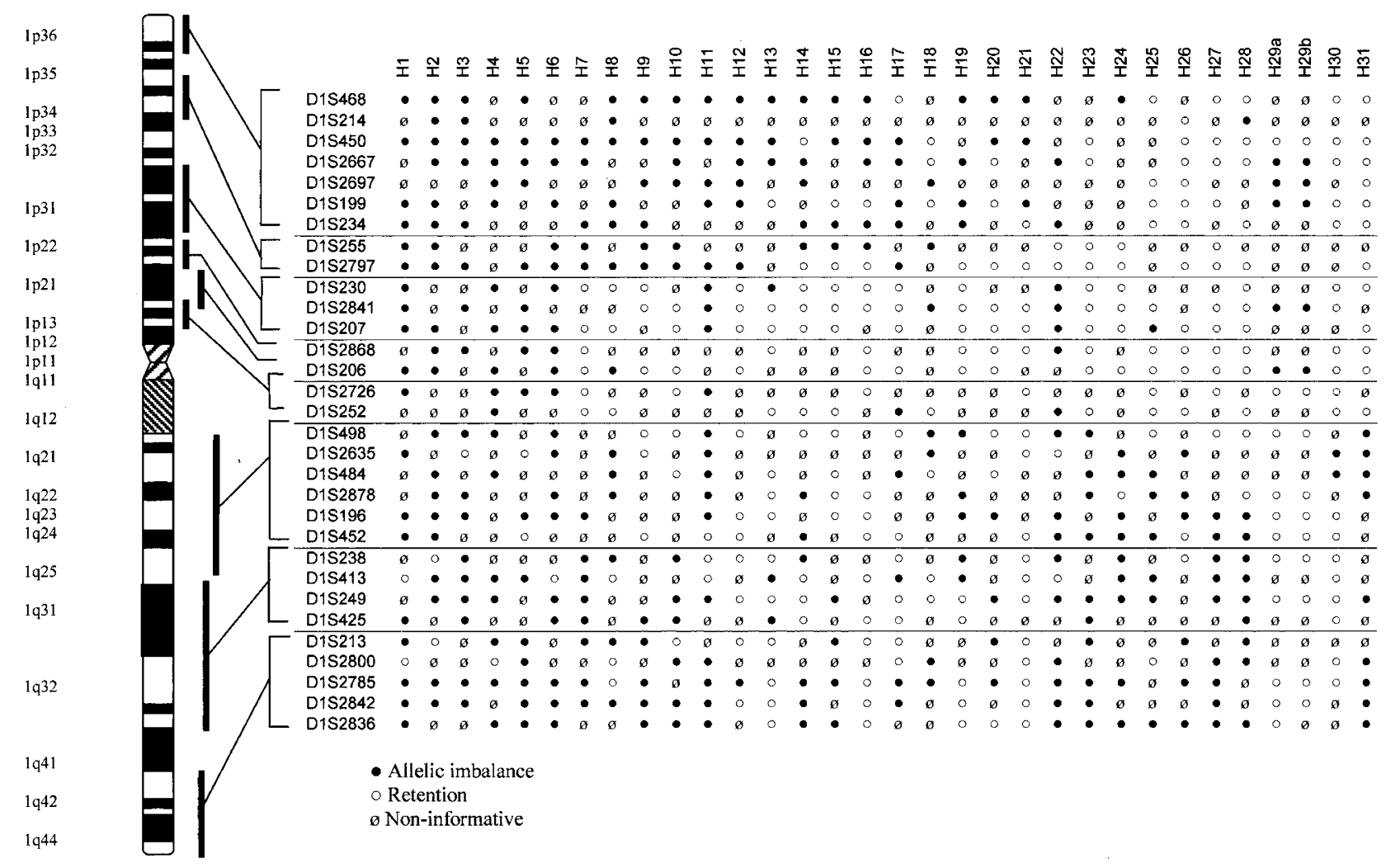

FIGURE 2. Summary of chromosome 1 allelic imbalances detected in 31 cases of hepatocellular carcinoma. The microsatellite markers are listed in order from telomere of $\mathrm{p}$-arm to telomere of q-arm. Their corresponding locations are listed on the left of the ideogram. At a given locus, tumorspecific allelic imbalance is indicated by a filled circle; retention of heterozygosity by an open circle, and noninformative (constitutional homozygosity) by a hatched circle.

H31) and there were absence of aberration as defined by CGH[0]microsatellite analysis[0] in 5 cases (H12, H16, H21, H29, and H30). The overall concordance rate on 1q31-q32 was $61 \%$ ( $19 / 31$ cases). In 1q42$\mathrm{q} 44$, CGH $[+]$ microsatellite analysis[+] was found in 15 cases (H1-6, H10, H11, H14, H15, H18, H24, H26, $\mathrm{H} 28$, and $\mathrm{H} 31$ ), and $\mathrm{CGH}[0]$ microsatellite analysis[0] in 5 cases (H16, H19, H21, H29, and H30). An overall concordant rate of $65 \%$ (20/31 cases) was suggested on 1q42-q44.

\section{DISCUSSION}

Transformation of normal hepatocytes to hepatocellular carcinoma will, as with other solid tumors, involve activation of oncogene and inactivation of tumor suppressor genes, all of which will lead to increasing genetic instability and loss of cell cycle control. In hepatocellular carcinoma, the role of proto-oncogene(s) and tumor suppressor gene(s) on common gains of $1 \mathrm{q}$ and $\mathrm{LOH}$ on $1 \mathrm{p} 36-\mathrm{p} 34$ respectively has been implicated. In this study, patients examined were predominantly chronic hepatitis B virus carriers who were derived from a racially and etiologically homogenous population in southern China. The simultaneous CGH and microsatellite analysis on chromosome 1 has enabled the consistently over- and underrepresented regions on chromosome 1 to be defined. ]Although CGH suggested minimal overlapping regions on 1p36-p35, 1q21-q25, and 1q32-qter, microsatellite analysis has further refined chromosome 1 abnormalities to four distinct SORs at 1p36.13-p36.22, 1q23.1-1q23.3, 1q25.1-q31.1, and 1q43.

Our finding of a smallest deleted region on 1p36.13-p36.22 (D1S199 to D1S2667) that flanked approximately $10 \mathrm{cM}$ was similar to that identified by Fang et al. (10). Frequent LOH on chromosome 1p36 has been implicated in the progression of intrahepatic cholangiocarcinoma, the second most common liver malignancy (11), and has also been well documented in neuroblastomas (12). Although allelic losses on 1 p36 have been suggested to be associated with poor differentiated histologic grade in epithelial ovarian carcinoma (13), deletions on 1 p36.12 were found in the early dysplastic lesions and cirrhotic nodules of hepatocellular carcinoma (7). A role for 1 p36 deletions in the early events of hepatocarcinogenesis was thus further enforced. Several tumor suppressor genes have been described in $1 \mathrm{p} 36$. These include TP73, DFFA, and RIZ $(10,14,15)$. Structurally and functionally, TP73 (at 1p36.33) is related to TP53. However, the tumor suppressor function of TP73 as a target essential to 


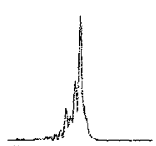

H12
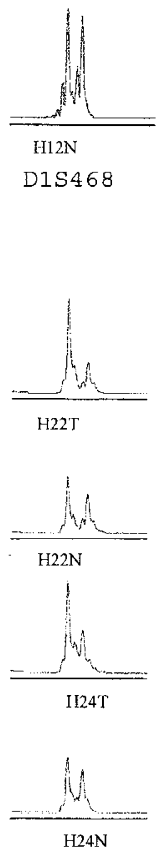

D1S196

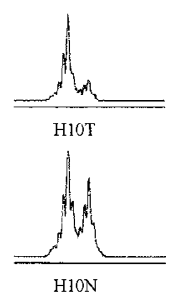

D1S450

c
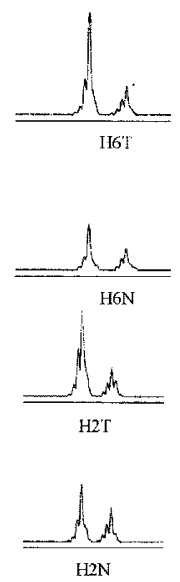

D1S249

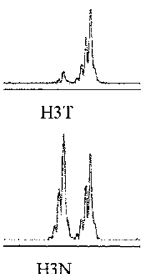

D1S2667

d
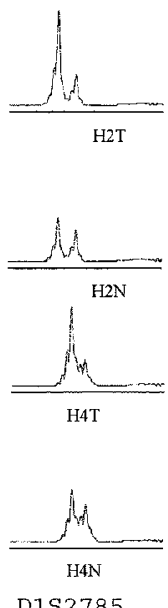

FIGURE 3. Examples of allelic imbalances detected in hepatocellular carcinoma. A, allelic loss of three markers on 1p, D1S468, D1S450, and D1S 2667, were detected in HCC cases H3, H10, and H12. B-D, cases H2, H4, H6, H22 and H24 displayed allelic imbalances at 1q markers, D1S196, D1S249, and D1S2785, which were localized at regions 1q23.1-q24.2, 1q32.1, and 1q43-q44, respectively. Allelic gains on 1q were suggested. T, tumor of the patient. $\mathrm{N}$, corresponding lymphocytes of the same patient.

the development of hepatocellular carcinoma has been excluded (16). The DFFA gene mapped to 1p36.22 encodes the active subunit of the apoptotic nuclease DNA fragmentation factor (DFF45) (17). Although DFFA has been reported to be homozygously deleted in a neuroblastoma cell line, the role of DFFA in human liver carcinogenesis remains to be investigated (12). Thus far, $R I Z$ is the only tumor suppressor gene that has been suggested in the pathogenesis of hepatocellular carcinoma (18).

Although gain of $1 \mathrm{q}$ has been considered as secondary karyotypic changes in hematological malignancies $(19,20)$, cytogenetic studies have indicated the most frequent structural alteration in hepatocellular carcinoma to be unbalanced $1 \mathrm{q}$ translocations that resulted from $1 \mathrm{q}$ gain $(21,22)$. This in turn would suggest aberrant $1 \mathrm{q}$ to be a primary karyotypic event in the liver tumorigenesis. By CGH, we have identified, in the current hepatocellular carcinoma series, two minimal amplified regions at 1q21-q25 and 1q32-qter. High-level gain has previously been mapped to $1 \mathrm{q} 12-\mathrm{q} 22$ in hepatocellular carcinoma $(6,23)$, and common allelic imbalances suggested on 1q22-q23 (2). Gains in chromosomal region 1q23 have been proposed in drug-resistant phenotype in neuroblastoma pa- tients (24) and suggested to be associated with metastases in well-differentiated liposarcoma (25). Within the current SOR identified, 1q23.1-1q23.3, candidate genes described included TRK protooncogene (26) and $P B X 1$, a human homeobox gene involved in $\mathrm{t}(1 ; 19)$ translocation in acute pre-B-cell leukemias (27).

Specific regions on $1 \mathrm{q}$ have been implicated in the pathogenesis of human cancers. High-level amplifications of 1q25 described in metastatic prostate cancer (28) also displayed copy number gain of candidate gene $\mathrm{HPCl}$ (at 1q24-q25) in the advanced stage cancers (29). Allelic imbalances of the same region have also been reported in the progression of cervical carcinoma (30). High-density mapping on chromosome 1 indicated common allelic imbalances on 1q31-q32 in medulloblastoma and breast cancer $(31,32)$, and by linkage analysis on high-risk prostate cancer families, the predisposing gene for early-onset prostate cancer, $P C A P$, has been localized on 1q42.2-43 $(33,34)$. Although target genes within common SOR regions identified on $1 \mathrm{q}$ in liver carcinogenesis remained to be verified, our findings, and those from other research groups, strongly suggested the presence of genes 
residing on these chromosomal regions in cancer progression.

In the 31 primary hepatocellular carcinoma cases studied, the overall concordance between CGH and microsatellite analysis findings was $65 \%$ for $1 p, 74 \%$ for $1 \mathrm{q} 21-\mathrm{q} 25,61 \%$ for $1 \mathrm{q} 31-\mathrm{q} 32$ and $65 \%$ for $1 \mathrm{q} 42-$ q44. The remaining disconcordant cases can be sub-divided into two groups, the first group being allelic imbalance detected by microsatellite analysis but not by CGH. This might be due to the lower resolution of CGH analysis that precluded detection of regions smaller than $10 \mathrm{Mb}$. In addition, some cases demonstrated loss of the whole p-arm by microsatellite analysis but showed absence of imbalances by CGH. This might have been due to a loss of p-arm accompanied by reduplication of the remaining allele resulting in no net gain or loss of chromosomal material. The second group included cases that could be detected by CGH as gains or losses but not by microsatellite analysis. Although CGH has a lower resolution in detecting regional gains and losses, it has a higher sensitivity in identifying low-level copy gains or losses.

In conclusion, our combined CGH and microsatellite analysis studies on chromosome 1 have enabled deletion boundaries on $1 p$ and regions of allelic gains on $1 \mathrm{q}$ to be defined. The SORs identified may have implications for inactivation of tumor suppressor gene(s) at $1 \mathrm{p} 36.13-\mathrm{p} 36.22$ and activation of proto-oncogenes on 1q23.1-q23.3, 1q25.1-q31.1, and 1q43 in the development and progression of hepatocellular carcinoma.

Acknowledgments: This work was carried out within the Hong Kong Cancer Genetics Research Group that was supported by The Kadoorie Charitable Foundations, Hong Kong and the RGC earmarked grant (Ref. no.: CUHK 4044/01M). The authors are also grateful to the Providence Foundation Limited, Hong Kong, for their continuing support.

\section{REFERENCES}

1. Kuroki T, Fujiwara Y, Tsuchiya E, Nakamori S, Imaoka S, Kanematsu T, et al. Accumulation of genetic changes during development and progression of hepatocellular carcinoma: loss of heterozygosity of chromosome arm 1p occurs at an early stage of hepatocarcinogenesis. Genes Chromosomes Cancer 1995;13:163-7.

2. Nagai H, Pineau P, Tiollais P, Buendia MA, Dejean A. Comprehensive allelotyping of human hepatocellular carcinoma. Oncogene 1997;14:2927-33.

3. Simon D, Knowles BB, Weith A. Abnormalities of chromosome 1 and loss of heterozygosity on $1 p$ in primary hepatomas. Oncogene 1991;6:765-70.

4. Kusano N, Shiraishi K, Kubo K, Oga A, Okita K, Sasaki K. Genetic aberrations detected by comparative genomic hybridization in hepatocellular carcinomas: their relationship to clinicopathological features. Hepatology 1999;29:1858-62.
5. Marchio A, Meddeb M, Pineau P, Danglot G, Tiollais P, Bernheim A, et al. Recurrent chromosomal abnormalities in hepatocellular carcinoma detected by comparative genomic hybridization. Genes Chromosomes Cancer 1997;18:59-65.

6. Wong N, Lai P, Lee SW, Fan S, Pang E, Liew CT, et al. Assessment of genetic changes in hepatocellular carcinoma by comparative genomic hybridization analysis: relationship to disease stage, tumor size, and cirrhosis. Am J Pathol 1999;154:37-43.

7. Sun M, Eshleman JR, Ferrell LD, Jacobs G, Sudilovsky EC, Tuthill R, et al. An early lesion in hepatic carcinogenesis: loss of heterozygosity in human cirrhotic livers and dysplastic nodules at the 1p36-p34 region. Hepatology 2001;33:141524.

8. Terris B, Ingster O, Rubbia L, Dubois S, Belghiti J, Feldmann $\mathrm{G}$, et al. Interphase cytogenetic analysis reveals numerical chromosome aberrations in large liver cell dysplasia. J Hepatol 1997;27:313-9.

9. Kallioniemi A, Kallioniemi OP, Sudar D, Rutovitz D, Gray JW, Waldman F, et al. Comparative genomic hybridization for molecular cytogenetic analysis of solid tumors. Science 1992; 258:818-21.

10. Fang W, Piao Z, Simon D, Sheu JC, Huang S. Mapping of a minimal deleted region in human hepatocellular carcinoma to 1 p36.13-p36.23 and mutational analysis of the RIZ (PRDM2) gene localized to the region. Genes Chromosomes Cancer 2000;28:269-75.

11. Momoi H, Okabe H, Kamikawa T, Satoh S, Ikai I, Yamamoto M, et al. Comprehensive allelotyping of human intrahepatic cholangiocarcinoma. Clin Cancer Res 2001;7:2648-55.

12. Chen YZ, Soeda E, Yang HW, Takita J, Chai L, Horii A, et al. Homozygous deletion in a neuroblastoma cell line defined by a high-density STS map spanning human chromosome band 1p36. Genes Chromosomes Cancer 2001;31:326-32.

13. Alvarez AA, Lambers AR, Lancaster JM, Maxwell GL, Ali S, Gumbs C, et al. Allele loss on chromosome 1p36 in epithelial ovarian cancers. Gynecol Oncol 2001;82:94-8.

14. Jensen SJ, Sulman EP, Maris JM, Matise TC, Vojta PJ, Barrett JC, et al. An integrated transcript map of human chromosome 1p35-p36. Genomics 1997;42:126-36.

15. Yang HW, Chen YZ, Piao HY, Takita J, Soeda E, Hayashi Y. DNA fragmentation factor 45 (DFF45) gene at 1 p36.2 is homozygously deleted and encodes variant transcripts in neuroblastoma cell line. Neoplasia 2001;3:165-9.

16. Herath NI, Kew MC, Whitehall VL, Walsh MD, Jass JR, Khanna KK, et al. p73 is up-regulated in a subset of hepatocellular carcinomas. Hepatology 2000;31:601-5.

17. Judson H, van Roy N, Strain L, Vandesompele J, Van Gele M, Speleman F, et al. Structure and mutation analysis of the gene encoding DNA fragmentation factor 40 (caspaseactivated nuclease), a candidate neuroblastoma tumor suppressor gene. Hum Genet 2000;106:406-13.

18. Jiang G, Liu L, Buyse IM, Simon D, Huang S. Decreased RIZ1 expression but not RIZ2 in hepatoma and suppression of hepatoma tumorigenicity by RIZ1. Int J Cancer 1999;83:541-6.

19. Rooney PH, Murray GI, Stevenson DA, Haites NE, Cassidy J, McLeod HL. Comparative genomic hybridization and chromosomal instability in solid tumors. Br J Cancer 1999;80: 862-73.

20. Rowley JD. Mapping of human chromosomal regions related to neoplasia: evidence from chromosomes 1 and 17. Proc Natl Acad Sci U S A 1977;74:5729-33.

21. Parada LA, Hallen M, Tranberg KG, Hagerstrand I, Bondeson L, Mitelman F, et al. Frequent rearrangements of chromosomes 1, 7, and 8 in primary liver cancer. Genes Chromosomes Cancer 1998;23:26-35.

22. Wong N, Lai P, Pang E, Leung TW, Lau JW, Johnson PJ. A comprehensive karyotypic study on human hepatocellular carcinoma by spectral karyotyping. Hepatology 2000;32:1060-8. 
23. Qin LX, Tang ZY, Sham JS, Ma ZC, Ye SL, Zhou XD, et al. The association of chromosome $8 \mathrm{p}$ deletion and tumor metastasis in human hepatocellular carcinoma. Cancer Res 1999;59: 5662-5.

24. Hirai M, Yoshida S, Kashiwagi H, Kawamura T, Ishikawa T, Kaneko M, et al. 1q23 gain is associated with progressive neuroblastoma resistant to aggressive treatment. Genes Chromosomes Cancer 1999;25:261-9.

25. Forus A, Larramendy ML, Meza-Zepeda LA, Bjerkehagen B, Godager LH, Dahlberg AB, et al. Dedifferentiation of a welldifferentiated liposarcoma to a highly malignant metastatic osteosarcoma: amplification of 12q14 at all stages and gain of 1q22-q24 associated with metastases. Cancer Genet Cytogenet 2001;125:100-11.

26. Morris CM, Hao QL, Heisterkamp N, Fitzgerald PH, Groffen J. Localization of the TRK proto-oncogene to human chromosome bands 1q23-1q24. Oncogene 1991;6:1093-5.

27. Monica K, Galili N, Nourse J, Saltman D, Cleary ML. PBX2 and PBX3, new homeobox genes with extensive homology to the human proto-oncogene PBX1. Mol Cell Biol 1991;11: 6149-57.

28. Alers JC, Rochat J, Krijtenburg P-J, Hop WCJ, Kranse R, Rosenberg $\mathrm{C}$, et al. Identification of genetic markers for prostatic cancer progression. Lab Invest 2000;80:931-42.
29. Cher ML, Bova GS, Moore DH, Small EJ, Carroll PR, Pin SS, et al. Genetic alterations in untreated metastases and androgen-independent prostate cancer detected by comparative genomic hybridization and allelotyping. Cancer Res 1996;56:3091-102.

30. Cheung TH, Chung TK, Poon CS, Hampton GM, Wang VW, Wong YF. Allelic loss on chromosome 1 is associated with tumor progression of cervical carcinoma. Cancer 1999;86: 1294-8.

31. Benitez J, Osorio A, Barroso A, Arranz E, Diaz-Guillen MA, Robledo M, et al. A region of allelic imbalance in 1q31-32 in primary breast cancer coincides with a recombination hot spot. Cancer Res 1997;57:4217-20.

32. Pietsch T, Koch A, Wiestler OD. Molecular genetic studies in medulloblastomas: evidence for tumor suppressor genes at the chromosomal regions 1q31-32 and 17p13. Klin Padiatr 1997;209:150-5.

33. Gibbs M, Chakrabarti L, Stanford JL, Goode EL, Kolb S, Schuster EF, et al. Analysis of chromosome 1q42.2-43 in 152 families with high risk of prostate cancer. Am J Hum Genet 1999;64:1087-95.

34. Goode EL, Stanford JL, Peters MA, Janer M, Gibbs M, Kolb S, et al. Clinical characteristics of prostate cancer in an analysis of linkage to four putative susceptibility loci. Clin Cancer Res 2001;7:2739-49. 